\title{
Medicinal and bioorganic chemistry: an Austrian perspective of the chemistry-biology interface
}

\author{
Michael Schnürch ${ }^{1}$ Marko D. Mihovilovic ${ }^{1}$
}

Received: 3 February 2016/Accepted: 3 February 2016/Published online: 23 February 2016

(C) Springer-Verlag Wien 2016

Dear readers,

The present issue of Chemical Monthly is dedicated to a "paper-mini-symposium" on medicinal and bioorganic chemistry. In 2015, the Medicinal Chemistry Division of the Austrian Chemical Society (GÖCH) organized the third mini-symposium on aspects of the above areas at the interface of chemistry and biology. This event was embedded in the bi-annual conference "Chemistry Days" of the society, which covers all fields of chemistry in Austria. The series of mini-symposia on medicinal and bioorganic chemistry was established in 2011 in Linz; the edition in Graz 2013 was organized in cooperation with the thematic branch of the Hungarian Chemical Society; the 2015 event in Innsbruck was successfully implemented in close interaction with the corresponding branches of the Italian Chemical Society. As this one-day meeting bridging chemistry and biology has by now matured to a regular interdisciplinary workshop bringing together scientists with a diverse background, GÖCH and Springer decided to pick up the momentum and further promote such successful events in association with the society. This issue represents a first edition of extending a scientific meeting under the auspices of GÖCH to a printed version; it includes contributions by several presenters at the Mini-Symposium on Medicinal and Bioorganic Chemistry, complemented by regular submissions to Chemical Monthly with matching

Michael Schnürch

michael.schnuerch@tuwien.ac.at

Marko D. Mihovilovic

marko.mihovilovic@tuwien.ac.at

1 Institute of Applied Synthetic Chemistry, Vienna University of Technology, 1060 Vienna, Austria topics. Consequently, it features an Austrian perspective of the cross-roads of chemical and biological research with an international flavor.

The guest editors of this special issue are particularly grateful to the editorial executives at Springer for supporting this initiative and the Medicinal Chemistry Division. We do hope that this tribute to a highly active and interdisciplinary field in chemical sciences will act as a role model for future special issues with Chemical Monthly.

The current special issue additionally marks a caesura for the Medicinal Chemistry Division within GÖCH. After 8 years of acting as president of the division, Prof. Marko D. Mihovilovic will hand over the duty of executive head to Prof. Michael Schnürch. He properly represents the next generation of scientists at the chemistry-biology interface, and this change will ensure the high dynamics of the division in the years to come.

Sincerely,

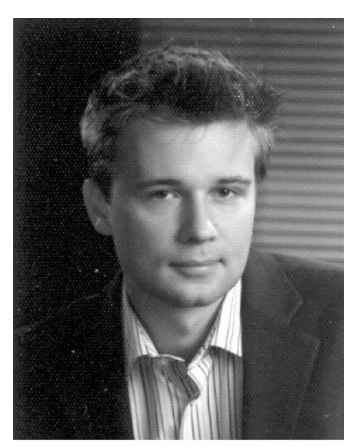

Michael Schnürch

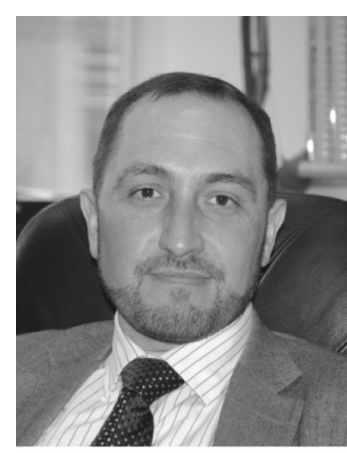

Marko D. Mihovilovic
Guest editors 